\title{
"El oro de América". La contribución de los emigrantes del Plata al tesoro de la Unión Republicana
}

\author{
Ignacio García
}

University of Western Sydney

El artículo describe el contexto en el que nace la Liga Republicana Española en Buenos Aires en 1903 y las circunstancias que llevan a su desaparición. En él se argumenta que los ataques sectarios de su ala lerrouxista contra los salmeronianos tornaron estéril el movimiento, haciendo que "el oro de América" que los emigrantes buscaban que sirviera a la Unión Republicana para regenerar a España, sirviese sólo como arma de propaganda a la Monarquía.

\section{Introducción}

Cuando los franquistas acuñaron la expresión "el oro de Moscú" —el que la Segunda República envió a la URSS y que según la propaganda de Madrid era utilizado para financiar las actividades del Partido Comunistano hicieron sino repetir una fórmula ya ensayada con éxito a principios de siglo por los monárquicos: la de "el oro de América", que los mauristas utilizaron contra los republicanos, después de que el éxito de estos últimos en las elecciones de 1903 hiciera tambalear el régimen de la Restauración. Lo que el comunismo español se beneficiara o no de ese famoso oro no es tema de este artículo, pero sí nos consta que el ya más olvidado "oro de América", a los republicanos, exceptuando quizás a Alejandro Lerroux y sus allegados, más que beneficiarles les perjudicó. Que el esfuerzo de los emigrantes españoles en el Plata por apoyar a esa República que iba a "regenerar" España sirviese únicamente para agudizar la crisis del propio movimiento republicano es una más de esas ironías que tiene la Historia. El fracaso no es sólo atribuible a la reacción monárquica. Los movimientos sociales, y el que generó la Liga Republicana Española en Buenos Aires no fue una excepción, surgen siempre limitados no sólo por resistencias externas, fáciles al menos de identificar si no de contrarrestar, sino sobre todo por resistencias internas, que casi siempre resultan más letales.

Ángel Duarte desempolvó en 1998 la olvidada página del republicanismo español en el Plata. No estaba mal preparado para hacerlo, conociendo como ha demostrado el movimiento republicano español de la épo- 
ca, y en particular el lerrouxismo. La república del emigrante describe en detalle la cultura política de la emigración española a principios de siglo. ${ }^{1}$ Interesante como es, no está exento de cierta superficialidad y parcialidad: no examina todas las fuentes disponibles, se apoya prácticamente sólo en las lerrouxistas. El ambicioso objetivo de este pequeño trabajo es el de completarlo. Me centraré en la actividad política en el seno de la Liga, y utilizaré como fuentes principales no sólo La República Española y las comunicaciones diplomáticas en que Duarte se basa, sino también la revista España, que él ignora para el período 1904-06. ${ }^{2}$ Me interesa sobre todo describir cómo surge este movimiento, único en su tipo en la historia de la emigración española, y analizar las fuerzas externas e internas que le dan forma, que lo conducen del entusiasmo inicial a la apatía. Mi investigación me lleva a veces a interpretaciones distintas a las de Duarte, a las que aludiré en notas a pie de página. Salvadas estas discrepancias, la mejor lectura de este artículo sería la que tuviera ese libro como trasfondo.

\section{De la Patriótica a la Liga}

La actividad política de los republicanos españoles en América, centrada en apoyar económicamente a sus correligionarios en la Península, no comienza con la constitución de la Liga en 1903; precede incluso a la Revolución de 1868. Aunque anecdótico, bien puede servirnos de antecedente el caso de José Paul y Angulo. Famoso por sus vitriólicos artículos en El Combate (1871), se le consideró cómplice, si no autor, del atentado que costó la vida al general Juan Prim, tras cuya muerte se exiló. En Europa, sus pasos se cruzaron con los del ex-sacerdote Romero Jiménez, cabecilla en Málaga de la primera sublevación federal en diciembre de 1868, también en exilio tras haber sido condenado a muerte y amnistiado. Volvieron a juntarse en Buenos Aires, Romero entonces fundador y alma del diario El Correo Español. Tras una estrecha amistad, Paul le causó la muerte, en duelo, en 1880. Hizo dinero más tarde con el proyecto para la ampliación de lo que fue el Dock Sud. Se dirigió después a París, donde pensaba utilizar sus acciones para apoyar una revuelta republicana, pero el

1 Duarte, Angel: La república del emigrante, Lleida, 1998; de entre los trabajos de este autor sobre el republicanismo cabe destacar: El republicanisme català a la fi de segle XIX, Vic, 1987.

2 Los artículos de Malagarriga y Fuente en La Republicana Argentina y en El Correo Español se citan a veces de Malagarriga, Carlos: Prosa muerta, Buenos Aires, 1908, y Fuente, Ricardo: Patria y República, Buenos Aires, 1904. 
derrumbe financiero de 1890 dio al traste con su fortuna. Manuel Ruiz Zorrilla le hizo el vacío y murió allí, en la miseria, en 1892. Las acciones que llevó no tuvieron valor alguno, pero fue con ellas que nació el mito de "el oro de América" que nos ocupa. ${ }^{3}$

Uno de los escasos amigos de Paul y Angulo en el Plata fue Rafael Fernández Calzada, que emigró en septiembre de 1874, tras haber asistido como corresponsal de La Discusión, el periódico de Pi i Margall, a la última sesión parlamentaria de la República. Presidente de 1886 a 1891 del elitista Club Español, presentó como tal a Isaac Peral en un homenaje que se celebró en 1888 a dos entonces recién llegados que con él protagonizarán la aventura de la Liga Republicana: Antonio Atienza y Medrano y Carlos Malagarriga. ${ }^{4}$

Discípulo de Julián Sanz del Río, Atienza comenzó su tarea de periodista republicano en El Pueblo en 1871, defendiendo la política de Nicolás Salmerón. Fue uno de los fundadores de la Institución Libre de Enseñanza, cuyo Boletín llegó en un momento a dirigir. Fue candidato por Almería en las elecciones de 1886 y uno de los firmantes de la moción que en la asamblea de Madrid de 25 de enero de 1887 consumó la ruptura de la precaria unión que por años mantuvieron Salmerón y Ruiz Zorrilla. Actuó de secretario del Partido Republicano Centralista que entonces fundó Salmerón y dirigió su periódico, La Justicia. ${ }^{5}$ Carlos Malagarriga había desarrollado una intensa actividad en El Día, en 1880, y El Progreso, que dirigirá en 1884. Fundó El Pueblo en 1887, que se refundió más tarde con El País, al frente del cual estuvieron Alejandro Lerroux y después Ricardo Fuente. Su defensa del zorrillismo le había costado antes de emigrar siete procesos y tres meses de cárcel. ${ }^{6}$

3 Véase, Gómez Aparicio, Pedro: Historia del periodismo español, Madrid, 1971, págs. 146165; Paul y Angulo es uno de los personajes principales en Pérez Galdós, Benito: La España trágica, Madrid, 1909. Sobre su paso por Argentina, véase Berenguer Carisomo, Arturo: España en la Argentina, Buenos Aires, 1953, págs. 68 y 72-76; y Calzada, Rafael: Cincuenta años en América, Buenos Aires, tomo II, págs. 57-68.

4 Calzada: Cincuenta años, pág. 144. Sobre Calzada, además, Villegas, Emilio F. de: Reseña histórica del Club Español, 1852-1912, Buenos Aires, 1912; "Rafael Calzada, candidato a diputado a Cortes por Madrid”, La República Española, Buenos Aires, 27 de julio de 1905; Dedeu, Martín: Nuestros hombres en Argentina. Dr Rafael Calzada, Buenos Aires, 1913; y Biagini, Hugo: Intelectuales y políticos españoles a comienzos de la inmigración masiva, Buenos Aires, 1995, págs. 161-182.

5 Dedeu, Martín: “Antonio Atienza y Medrano", La República Española, Buenos Aires, 15 de noviembre de 1903; y "Antonio Atienza y Medrano, de El Radical de Almería”, España, Buenos Aires, segundo semestre de 1906, pág. 169; Biagini, Intelectuales y políticos..., págs. 149-160.

6 Daufí, Miguel: "Carlos Malagarriga", La República Española, Buenos Aires, 15 de noviembre de 1903; y Dedeu, Martín: "Nuestros hombres en la Argentina. Dr. Carlos Malagarriga", Hispania, Buenos Aires, 1 de enero de 1912. 
La velada que Calzada organizó en honor a Peral —el inventor del submarino a quien, se decía, tantas zancadillas le pusieron por sus inclinaciones republicanas - merece especial mención. La colonia, como la Península, se había dividido en peralistas y antiperalistas, primando en Buenos Aires con mucho los primeros, que constituyeron numerosos comités para recaudar dinero que enviar a Peral para permitirle continuar sus ensayos. Aunque la campaña se centró en el hombre, no en el republicanismo, supuso un antecedente importante, sobre todo teniendo en cuenta que fue sobre la base de esta red de comités que se constituirían después los de la Asociación Patriótica y los de la Liga Republicana. ${ }^{7}$

Es importante que nos refiramos a la Patriótica porque es la que crea el contexto que permitirá el surgimiento de la Liga. En 1895 comienza la guerra de Cuba. La xenofobia antiespañola en Argentina alcanzó cotas nunca superadas. Lejos de amedrentarse, la colonia respondió creando en marzo de 1896 esta asociación para "[r]esponder al llamamiento de la Patria siempre que necesite el concurso, bien personal, bien intelectual o pecuniario de sus hijos" y para "[s]alir en defensa del buen nombre y el honor de España cuando fuese necesario". Tomando como punto de partida los mencionados comités Peral, se creó una mucho más amplia red de comités que a través de perfectamente orquestadas campañas recogieron, en números redondos, 2.190.000 pesos en la Suscripción Pro Barco, con la que se compró a España el crucero acorazado Río de la Plata, y 2.258.000 que se enviaron a la Suscripción Nacional que para gastos de guerra convocó la Reina Regente en 1898; a lo que habría que sumar los 58.000 que ya se habían donado a un comité patriótico establecido en 1895 para facilitar el envío de casi dos mil voluntarios que partieron desde Buenos Aires a las Antillas. Un total de más de cuatro millones y medio que, dividido por los doscientos mil españoles entonces residentes en Argentina, supuso una contribución per capita que se ha calculado en 22.5 pesos. ${ }^{8}$ Cabe destacar la extraordinaria transparencia con que se condujeron estas suscripciones. Como ya se había hecho en tiempos de los comités Peral, todas las aporta-

7 Sobre Peral, Gómez Aparicio, Historia del periodismo..., págs. 550-554. En Argentina, Calzada, Cincuenta años..., tomo I, págs. 410-411.

8 Cálculo del autor. Sobre la Patriótica, García, Ignacio: "El 2 de mayo de 1898 en el Teatro Victoria de Buenos Aires", Journal of Iberian and Latin American Studies, vol. 3, núm. 2, Melbourne, 1997, págs. 33-53; "Voluntarios españoles del Río de la Plata en la guerra cubano-hispano-norteamericana”, Cuadernos Hispanoamericanos, núms. 577-578, Madrid, 1998, págs. 113-129; y “... y a sus plantas rendido un león. Xenofobia antiespañola en Argentina, 1890-1900”, Estudios Migratorios Latinoamericanos, núm. 39, Buenos Aires, 1998, págs. 195-221. 
ciones, grandes y pequeñas, aparecieron con nombre y apellidos en la primera página de $\mathrm{El}$ Correo, portavoz oficial de la asociación.

De crear una organización específica para los republicanos españoles se comienza a hablar tan pronto llegan a Argentina las noticias de la formación de la Unión Republicana. Valentín Marqueta lanzará la idea de constituir un Partido Republicano Revolucionario. Había sido militante zorrillista antes de emigrar en 1888. Tras luchar en las barricadas en la revolución de julio de 1890 en Buenos Aires, recorrió Brasil, Venezuela, Cuba y México. En este último país presumiría de ser uno de los iniciadores de la suscripción patriótica para donar a España 588 mulas, mil caballos "y el crucero Extremadura, mayor que el Río de la Plata "[sic]. . Volvió a Buenos Aires en 1898, fundando en 1901 el periódico anticlerical El Infierno.

En vísperas de las elecciones, insiste: "En Argentina viven republicanos ilustres que deben hacer un llamado a la colonia." A mediados de mes da cuenta de la formación de un comité republicano en Córdoba, publica cartas de apoyo de Rosario y Mendoza, y se pregunta por qué nada sucede aún en Buenos Aires. La agitación de El Infierno surte efecto: el 27 de abril, un grupo de republicanos firmaba un telegrama a Salmerón felicitándole por la victoria. Entre ellos, Rafael Calzada, Antonio Atienza, que acababa de ser elegido presidente de la Asociación Patriótica, Carlos Malagarriga, el propio Marqueta y Miguel Daufí, que había sido diputado en las Cortes Constituyentes durante el Sexenio Democrático. ${ }^{10}$ El exaltado partido que imaginó Valentín Marqueta pronto se transformó en la más templada Liga Republicana Española, que se constituyó el 7 de mayo en reunión que encabezó Daufí celebrada en el Hotel España. En una segunda reunión se eligió el comité central, presidido por Calzada. No figuró en él el propio Marqueta que, no obstante, declararía con la satisfacción del deber cumplido que la Liga era precisamente ese gran partido republicano que había venido predicando El Infierno. ${ }^{11}$

\section{El mitin del San Martín}

Calzada confesará en sus memorias que le costó mucho tomar la decisión de encabezar un movimiento de este tipo que, conociendo a la colec-

9 "Valentín Marqueta", Liga Republicana Española, Buenos Aires, 20 de diciembre de 1903; no existió tal barco.

10 El Infierno, Buenos Aires, 2, 6 y 30 de abril de 1903.

11 Ibídem, 14 de mayo de 1903. 
tividad, le parecía imposible que pudiera cuajar. La colonia, sin embargo, reaccionó con extraordinario entusiasmo, como no se había vuelto a ver desde los primeros años de la Patriótica, llegando al comité central adhesiones en calidad y número inesperadas, tanto de la capital como de provincias. De mayo de 1903 a febrero de 1904 se llegaron a constituir, sobre la base de los de la Patriótica, un centenar de comités. ${ }^{12}$

El Correo Español, buscando salir de una situación financiera deplorable, optó por convertirse en el órgano oficial de la Liga. Compitió como portavoz de los intereses republicanos con dos semanarios: Nueva España, que durante unos meses dirigió Miguel Daufí tras dimitir como vocal del comité central de la Liga para mantener su independencia, y La República Española, que fundó otro vocal, Eduardo Cañas Barco, éste sin dimitir. "Pertenecemos al comité central de la Liga", escribió en su primer número: "acataremos los acuerdos, pero aplaudiremos o censuraremos según veamos;" Malagarriga sería desde los primeros números colaborador habitual. ${ }^{13}$

Los republicanos de la Península reaccionaron con entusiasmo a la creación de la Liga. Salmerón, Lerroux y Vicente Blasco Ibáñez enviaron mensajes de apoyo. Costa escribió a Calzada satisfecho por tal "felicísima idea que acelerará aquí el cambio de régimen político". ${ }^{14}$ El diputado republicano José de Zulueta viajó a Buenos Aires acompañando una delegación comercial. Se anunció ya a comienzos de 1904 que también viajarían Lerroux y Blasco Ibáñez, aunque éstos tardaron años en hacerlo. ${ }^{15}$ En España, la opinión pública - monárquica y republicana- asociaba a la colonia española en el Plata con el crucero y las grandes cantidades de dinero que mandó la Patriótica en 1898, y por consiguiente se la presumía, no del todo con razón, numerosa y rica. Sí se acertó al establecer relación entre este movimiento republicano y el patriótico de 1895 a 1898.

Que la Patriótica estuviera liderada por el canovista Gonzalo Segovia y Ardisone, varias veces diputado a Cortes, no debe hacernos olvidar el peso decisivo que los republicanos jugaron en su seno. Quienes la promo-

12 Calzada: Cincuenta años..., pág. 222; comités de la Liga en Duarte: La república..., pág. 215 .

13 Más adelante se publicará también en El Imparcial, dirigido por Indalecio Cuadrado. Duarte: La república..., presenta a La República Española como reflejo fiel del republicanismo español en el Plata (pág. 98); aquí se argumenta que reflejó fielmente tan sólo a su corriente lerrouxista.

14 El Infierno, Buenos Aires, 16 de julio de 1903. La República Española, Buenos Aires, 30 de agosto y 6 de diciembre de 1903. La carta, de 5 de agosto de 1903, se reproduce en Ibídem, 6 de septiembre de 1903. 
vieron lo fueron: Fernando López Benedito, el director de $E l$ Correo y su presidente provisional, y Calzada, que redactó sus estatutos. Sirva de muestra, sin que la lista sea exhaustiva: en la primera junta de la Liga aparecen, además de Calzada, personalidades que destacan en los primeros años de la Patriótica: Antonio Varela Gómez, uno de sus promotores, Manuel Castro López y Manuel Durán que figuran en su primer comité, Avelino Gutiérrez, Atienza y el doctor Troncoso. ${ }^{16}$

El 15 de agosto de 1903, la Liga celebró su primer mitin en el Teatro San Martín. Siete mil personas asistieron, según El Correo; tres mil más quedaron en la calle. Hablaron, entre otros, Calzada, Malagarriga y Atienza, pero la estrella de la tarde fue un recién llegado: Ricardo Fuente. Había sustituido a Lerroux como director de El País de Madrid y fue con don Alejandro uno de los fundadores de la Federación Revolucionaria, antecedente inmediato de la Unión Republicana. ${ }^{17}$ Masón, escritor de novelas por entregas bajo el seudónimo de Antonio Asensio, su militancia republicana le forzó a exilarse a París. Al no conseguir en 1903 el escaño por Tortosa por el que se había presentado, tan pronto como se enteró de la constitución de la Liga en Buenos Aires viajó al Plata. Llegó rodeado de misterio, "en misión", dirá La República Española. ${ }^{18}$

La fama de Fuente precedió a su viaje. Corresponsal de La Nación en España, Rubén Darío había escrito sobre el periódico El País y quien fuera su director durante cinco años, con halagos tales como "sabe juntar... la autoridad al tino y la comprensión a la afabilidad... el tipo ideal de director para sus redactores", redactores, por otro lado, que se suponía habían de visitar la cárcel con cierta frecuencia. Cuenta como anécdota que su famoso artículo "El triunfo de Calibán" se publicó intacto en el periódico conservador La Época mientras que la censura lo mutiló severamente en $E l$ País. ${ }^{19}$ Nada más llegar a Buenos Aires, se incluyó a Fuente en el comité central de la Liga.

El 7 de julio de 1903, Salmerón pronunció un discurso que hizo mella entre los republicanos en Argentina. Basándose en documentos enviados al

15 La República Española, Buenos Aires, 6 de diciembre de 1903.

16 Primera junta en Duarte: La república..., págs. 213-216; aunque menciona a la Patriótica, a Duarte se le escapa la importancia que tuvo este movimiento, lo que no le ayuda a entender la situación en el Buenos Aires de 1903.

17 Suárez Cortina, Manuel: El reformismo en España. Republicanos y reformistas bajo la Monarquía de Alfonso XIII, Madrid, 1986, pág. 7.

18 "Ricardo Fuente", La República Española, Buenos Aires, 15 de noviembre de 1903.

19 Darío, Rubén: "La joven literatura", La Nación, Buenos Aires, 3 de marzo de 1899. 
Congreso por el Gobierno norteamericano, buscó demostrar que en 1898 se había peleado no tanto por defender la integridad de España como "el trono de un niño y la regencia de una austríaca". En el San Martín, Fuente arengaría:

"Vosotros, a quienes la derrota aniquiló moralmente porque sufristeis la vergüenza del desastre en tierra extranjera... ya sabéis qué hacían reyes y gobernantes mientras vosotros os quitabais el pan de la boca y reuníais millones para comprar un barco y contribuir a los gastos de la guerra. . . Se han burlado de vuestra candidez y de vuestro patriotismo". ${ }^{20}$

A estas revelaciones se sumó otra que también hería las fibras más sensibles de la colectividad: el Río de la Plata, se conocía a finales de 1903, había servido de barco de recreo a la familia real y se utilizaba en esos momentos para una visita de cumplido a los Estados Unidos. En el segundo multitudinario mitin que organiza la Liga, en diciembre de mismo año en el Teatro Victoria, con Zulueta como invitado especial, Malagarriga alude en su discurso al "hondo agravio que se inflige a la colonia" con ello. ${ }^{21}$

Una muestra más del enlace entre el movimiento patriótico de 1895-98 y el republicano de 1903: en la "Carta de los republicanos españoles a sus compatriotas" con la que se inicia la suscripción para el Tesoro republicano en noviembre de 1904, Rafael Calzada pedirá "hacer por la regeneración de la patria lo que en otro tiempo hicimos por su integridad y su honor." ${ }^{22}$ Como veremos, no se hizo tanto. La Patriótica, frente a la hostilidad porteña, reaccionó estrechando filas, con una generosidad que en palabras del ministro de España Julio de Arellano y Arróspide "ray[ó] en lo inverosímil y causó aquí general estupor". ${ }^{23}$ La Liga, hostigada por una Legación que aún preside Arellano, en lugar de reforzar su unidad se enzarzará en peleas internas.

\section{La reacción monárquica: Gedeón y las cruces}

Era la primera vez que una asamblea de tales dimensiones se convocaba fuera de España, señalaba Fuente en su discurso en el San Martín:

20 La República Española, Buenos Aires, 26 de julio de 1903.

21 Ibídem, 6 de diciembre de 1903.

22 Ibídem, 17 de noviembre de 1904.

23 Archivo Ministerio de Asuntos Exteriores, Madrid. Correspondencia Embajadas y Legaciones (en adelante, AMAE), 2314. Ministro de España a ministro de Estado, 1 de febrero de 1899. 
"Repercutirá como un trueno en el palacio de la Plaza de Oriente". ${ }^{24}$ Donde ciertamente repercutió fue en las oficinas de la Legación y entre los, pocos, monárquicos de la colonia.

Cuando se fundó la Liga, Arellano estaba fuera. Llegó justo en el momento en que se anunciaba el mitin del San Martín. En su informe a Madrid - que del ministerio se filtró a La Época y de ahí a los periódicos de Buenos Aires - indicó que nadie de peso dentro de la comunidad pertenecía al grupo republicano. Hasta en las "Páginas de España" que publicaba el más moderado de los republicanos, Justo Sanjurjo López de Gomara, en El Diario se pidió su dimisión. ${ }^{25}$ Se embarcó Arellano de nuevo en septiembre, quedando por años la Legación de Buenos Aires a cargo de Juan González de Salazar como encargado de negocios.

Con el apoyo de Madrid, la Legación buscó desacreditar y neutralizar a la Liga. Una de las estrategias que se utilizó fue la de inundar Buenos Aires con cruces - y con promesas de cruces- que se distribuyeron, en palabras de Calzada veinte años después, "en proporciones que seguramente no vuelvan a repetirse". Los republicanos vieron en ello, más que el deseo del gobierno de premiar a esas personas, el propósito de apartarles de la Liga o de impedir su ingreso en ella. ${ }^{26}$

Otra estrategia fue la de la difamación. Por esas fechas comenzó a circular por Buenos Aires un pasquín titulado Gedeón, en el que aparecían ridiculizados personajes relacionados con la Liga. Se trataba de una hoja intermitente que se repartía gratis a las personas relacionadas con aquellas a quienes se difamaba. Así por ejemplo, la podían recibir los socios residentes en la Península de comerciantes establecidos en Buenos Aires. Se trataba de minarles el crédito, de quitarles clientela. Muchos hombres de negocios se alejaron de la Liga ante el peligro de verse públicamente ridiculizados. Detrás de Gedeón resultó estar Ricardo Rodiño Iglesias, a quien Malagarriga llevó ante los tribunales. El acusado se retractó, con lo que quedó en libertad, resolución que Malagarriga consideró injusta. "Declaraba además que yo era un perfecto caballero, pero se suprimió esto a mi pedido, pues no me convenía semejante declaración en boca de Rodiño.” Detrás de Rodiño, los republicanos vieron la mano de González de Salazar, aunque, como reconoció el propio Malagarriga, se carecía de pruebas. ${ }^{27}$

24 La República Española, Buenos Aires, 23 de agosto de 1903.

25 Ibídem, 30 de agosto de 1903.

26 Calzada: Cincuenta años..., tomo II, pág. 224.

27 La República Española, Buenos Aires, 19 de julio, 15 de septiembre y 10 de noviembre de 1904. 
Se hizo famoso en la colonia un telegrama enviado por Salazar al ministerio con ocasión de las celebraciones en 1904 del aniversario de la República, telegrama que publicó El Imparcial de Madrid y, luego, todos los periódicos de Buenos Aires: "Banquete republicano. Fracaso. 200 personas. Dificultad en encontrar sitio por si no pagaban. Diputados argentinos rehusan. 6 personalidades se han separado. Continúo vigilando." Tarea la de vigilar nada fácil, ya que las autoridades argentinas no colaboraron a pesar de haber solicitado Salazar el apoyo del mismo presidente de la República: "Díjome que él tiene que tolerar toda clase de insultos... sin poder evitar su circulación". 28

La vigilancia de la Legación fue especialmente minuciosa en lo relacionado con la Patriótica, desde abril de 1903 presidida por Atienza. A un tris de desaparecer tras la derrota del 1898, hubo de continuar, si más no fuera que por completar las gestiones para la entrega del Río de la Plata a España. Bajo la presidencia de Atienza recuperó parte de su prestigio, en condiciones ya de celebrar los Juegos Florales que se habían promovido allá por 1897 como medio de fomentar la confraternidad hispano-argentina (y de recaudar dinero para el barco) y que se habían tenido que aplazar año tras año. La cuestión de si debía la Casa Real ofrecer un premio para estos Juegos Florales, a celebrarse el 12 de octubre de 1904, llegó a enfrentar a Salazar con Segovia, el más caracterizado monárquico de la colonia.

El presidente Roca había ofrecido ya su premio y Segovia, que continuaba como presidente de la comisión organizadora, pidió otro al intendente de la Casa Real ("Tema y premio de Su Magestad"). Madrid aprobó su concesión pero el encargado de negocios telegrafió su oposición al ministro de Estado. Sugirió que se enviase sólo si al renovarse la junta directiva triunfara la candidatura monárquica. Criticaba el marcado carácter republicano de la junta actual dando las razones del porqué el Gobierno español no debía dar calor a las iniciativas de la Patriótica.

"Si bien es cierto prestó en otras ocasiones relevantes servicios a España con sus fecundas iniciativas inspiradas en el más profundo patriotismo con abstracción de toda idea política a las cuales prestaron su concurso todos los españoles radicados en

28 Archivo General de la Administración Civil del Estado, Embajada Argentina (en adelante, AGA), 9095, 138. Del encargado de negocios al ministro de Estado, 22 de febrero de 1904. El telegrama se publicó en El Imparcial de Madrid el 13 de febrero de 1904 y lo reprodujo La República Española el 13 de marzo de 1904. La correspondencia de Salazar con el ministerio de Estado adjunta numerosos recortes de prensa, especialmente de El Correo Español, que relatan acontecimientos relacionados con las actividades republicanas de la Liga y la Patriótica. 
el país, no puede desgraciadamente decirse hoy lo mismo, por la marcada tendencia política de carácter republicano que ha tomado esa corporación coadyuvando a la propaganda republicana inaugurada en esta capital por la liga de ese nombre, como ya he manifestado a VE con personalidades de la Asociación Patriótica, cuyo presidente Sr. Atienza es vocal, el más influyente y de no escasa iniciativa, en los trabajos del grupo republicano, pudiendo VE formarse una idea de su calidad en el hecho de ser dicho Sr. periodista y miembro bastante notable de la redacción de La Prensa, diario que como VE no ignora, es el de más importancia por su gran circulación y más extensamente informado y cuya influencia como órgano del periodismo diario, se extiende con gran profusión a todos los países de América del Sur". ${ }^{29}$

La junta de la Patriótica siguió siendo republicana y reeligió a Atienza como presidente; el premio llegó, aunque finalmente quedó desierto ${ }^{30}$

No se limitó Salazar a entorpecer iniciativas con las que pudieran lucirse los republicanos, también apoyó otras que fomentaran el protagonismo de la Legación. La más destacada, el proyecto de construcción de un monumento a Isabel la Católica en Buenos Aires. Fueron los carlistas de $E l$ Legitimista los que sugirieron la idea y él la auspició con todas sus energías, lo cual no dejaba de ser peculiar. No fue tarea fácil, como explicaría a Madrid:

"El principal obstáculo... ha sido la falta de medios para darle la mayor publicidad posible, porque la prensa del país no quiere encargarse de ninguna cuestión política y los órganos de nuestra colectividad, El Correo Español y La República Española son los más encarnizados enemigos de las instituciones, de esta Legación de S. M. y hasta personalmente del que suscribe. Por fin, y no sin trabajo, he conseguido que $E l$ Diario, periódico argentino de gran circulación, lo publique en una correspondencia semanal que titula 'Páginas de España". ${ }^{31}$

Se formó una comisión y se habló de llamar a una suscripción. Los republicanos combatieron la idea y el Senado ni se tomó la molestia de considerar el proyecto de cesión de terreno para el monumento, con lo que pronto se disolvió el comité. Pero el daño a los republicanos ya estaba hecho: se eligió para lanzar el debate el mismo momento en que la Liga ponía en marcha la suscripción para el Tesoro republicano. Llevando la discusión a si el monumento que reflejase mejor el espíritu de confraterniza-

29 AMAE, 1354. Despacho de 4 de febrero de 1904.

30 España, II, 64, Buenos Aires, 1904, pág. 10. Duarte: La república..., pág. 117, se hace eco del comentario despectivo de Malagarriga hacia los Juegos Florales; pero debe tenerse en cuenta que el objetivo de Malagarriga en el artículo que se cita no es hacer crítica literaria sino descalificar a Atienza.

31 AGA, 9096, 140. Despacho de 17 de octubre de 1904. 
ción debía ser el de Isabel la Católica, o el de Cervantes, o el de Castelar, poniendo sobre el tapete el tema de la neutralidad política en el extranjero, se desvió la atención de la suscripción de la Liga. ${ }^{32}$

El caballo de batalla de Salazar en 1905 fue la candidatura de Rafael Calzada a diputado a Cortes. Informó en detalle directamente al ministro de las negativas consecuencias que tendría para el ánimo político de la colectividad, ahora relativamente calmado, la elección de Calzada

"cuya designación ha sido hecha para halagar no solamente a la persona indicada, que como es sabido fue el fundador de esa agrupación, sino también al núcleo de afiliados a ese programa político, de quienes se esperan elementos pecuniarios que habrían de ser destinados, si los obtuvieran, a los más reprobados fines"

advirtiendo que, "en cuanto sea posible, se evite el éxito de la candidatura del señor Calzada". ${ }^{33}$ Sería o no por los apremios del encargado de negocios, pero en esas elecciones se le escamoteó el acta a Calzada. Fue esta la última intervención destacada de Salazar en la colonia.

\section{Jacobinos, pacifistas y neutros o telesforistas}

Con ser duro el asalto que desde posiciones monárquicas sufrió la Liga Republicana, no fue tanto el daño como el que padeció a raíz de las desavenencias internas. Como en la Península, el republicanismo español en el Plata se movía entre dos polos: el representado por Salmerón, que daba la primacía a la acción política, y el representado por Lerroux que, recogiendo la tradición de Ruiz Zorrilla, se la daba a la acción revolucionaria. En Buenos Aires, Atienza era, por un lado, más salmeroniano que el propio Salmerón; de su boca, la palabra revolución salía todavía con más dificultad que de la del líder de la Unión. Malagarriga, que en los ochenta había militado en el zorrillismo, encabezaba el sector lerrouxista.

Calzada cumplió un destacado papel como cohesionador de las fuerzas republicanas. Hombre de fortuna, había viajado a España en tres ocasiones, cultivando el contacto con Pi y Margall y Ruiz Zorrilla. Visitó a este último en Londres en 1885 portando documentos secretos que José María

32 Malagarriga: Prosa muerta, págs. 96-100. Duarte: La república..., pág. 59, da a los carlistas el protagonismo sobre esta iniciativa, pero cobra importancia no cuando los carlistas lo proponen (septiembre de 1904), sino cuando la Legación lo apoya (noviembre).

33 AGA, 9098, 144. Despacho fechado el 17 de agosto de 1905. 
Esquerdo le había entregado en Madrid y, algunas fuentes también señalan, dinero. ${ }^{34}$ Tenido por federal, definió así su republicanismo a mediados de los noventa:

\begin{abstract}
"Aunque partidario, por arraigadas convicciones, del sistema federal, nunca fui un entusiasta políticamente de mi insigne maestro y amigo Pi y Margall. Siempre vi en él al profundo pensador, al eminente sociólogo, al varón probo, no al hombre de acción, al revolucionario; y convencido de que la República solo podría venir en España por el camino de la violencia, me sentí fuertemente inclinado al célebre don Manuel Ruiz Zorrilla". ${ }^{35}$
\end{abstract}

Siempre conciliador, su eclecticismo ideológico ayudó en los primeros momentos de la Liga, pero cuando surgieron, a espejo de las de España, las desavenencias en Buenos Aires, no fue dique que pudiera contenerlas. Su mayor logro fue el de mostrar a los emigrantes españoles en América que ser buen patriota no estaba reñido con la militancia republicana. Particularmente durante los años de la guerra, se había mantenido entre los españoles de América —asediados por una opinión pública hostil y buscando ofrecer un apoyo efectivo a la patria - la especie de que los españoles en el exterior debían ser sólo españoles. Se pretendía con ello salvaguardar la unidad y evitar bochornosos incidentes que reforzaran ante los americanos la imagen ya de por sí negativa que solían tener de España. En 1903, la conveniencia o no de que los emigrantes participaran en la política interna de España salió a la palestra a través de un sonado debate entre Calzada y Telesforo García.

Poco después del mitin del San Martín, el comité central de la Liga resolvió llamar a los correligionarios de las repúblicas americanas a constituir una Federación Republicana. A este efecto, Calzada redactó una carta que se envió a aquellas personas de las que se suponía simpatizaban con el republicanismo. Entre los contactos de la Liga estaba Telesforo García, uno de los líderes del movimiento patriótico de 1895-98 en México, de quien se decía había mantenido estrecha relación con Castelar. Telesforo, en vez de contestar privadamente a Calzada, mandó la carta a los periódicos madrileños acompañándola con un comentario en el que desautorizaba como patriota el movimiento argentino, basándose en "la conveniencia de

34 Se afirma que le entregó dinero en "Rafael Calzada. Datos biográficos", La República Española, Buenos Aires, 3 de agosto de 1905, y en Dedeu, "Dr Rafael Calzada"; no lo menciona el propio Calzada en Cincuenta años...

35 Calzada: Cincuenta años..., tomo II, pág. 17. 
que los españoles, fuera del suelo nacional, no seamos más que españoles" ${ }^{36}$ Los periódicos de Buenos Aires reprodujeron la carta de los de Madrid, a la que Calzada se vio obligado a replicar. "A Telesforo", señalaba, "la Monarquía le debe un favor. De haber sabido que el amigo del insigne Castelar pensaba así, no le hubiera escrito." ${ }^{37}$

Partidarios de la abstención eran la ínfima minoría monárquica, que encontraba en el argumento el instrumento ideal para atacar a los republicanos, y la gran mayoría de emigrantes a quienes no interesaba la política o no querían tomar parte activa en ella. En esa mayoría cabría incluir hasta aquellos que - como Telesforo García - se autodenominaban "republicanos". Para atacar a estos republicanos blandos en los años siguientes se utilizaría en la colonia española en Argentina el adjetivo "telesforista".

También se les llamó "neutros". El concepto de neutro, al parecer, lo acuñó Atienza en la revista España pero usaron y abusaron de él sobre todo Ricardo Fuente y Carlos Malagarriga. ${ }^{38}$ Minorías monárquicas y carlistas al margen, eran los neutros o telesforistas los que impedían el avance de la Liga. Dos estrategias se diseñaron para hacerles frente: por un lado, la de convencerlos a través de la persuasión para que se unieran a su causa; por el otro, la de combatirlos para obligarles a definirse como monárquicos o republicanos. Estrategias opuestas que correspondían a las dos corrientes de la Liga: la de los salmeronianos y la de los lerrouxistas o, como a partir del mitin del Teatro Victoria comenzarían a denominarse en Buenos Aires, la de los "pacifistas" y la de los "jacobinos".

Atienza pronunció el discurso inaugural en este mitin, por ausencia de Calzada. Defendió que a la república se debería ir por todos los medios justificados, e insistió en que él no era jacobino, y sería conservador en un gobierno republicano. Buscaba así acercar a la gran mayoría al proyecto republicano, porque éste era el de la regeneración de España y, a eso, no sólo los jacobinos, sino hasta incluso los monárquicos debieran colaborar. Le siguió Fuente en el uso de la palabra, y éste no pudo resistir la tentación de improvisar una respuesta a Atienza: no para refutar sus ideas, dirá, sino para afirmar las propias. Si Atienza no era jacobino, él sí. Más importante que lo que se dijo fue lo que se insinuó: que Atienza era un republicano

36 Unión Iberoamericana, Madrid, 31 de agosto de 1903.

37 La carta, de noviembre de 1903, se publicó después en folleto: Los republicanos españoles de América. Carta Abierta del Dr. Rafael Calzada, Presidente de la Federación Republicana Española de América a D. Telesforo García de México, Buenos Aires, 1907.

38 Así lo afirma Fuente: Patria y República, pág. 59. 
tibio, flojo, que había perdido los bríos de otros tiempos, un neutro cualquiera ${ }^{39}$ Aunque las divergencias ya se habían insinuado antes, es a partir de aquí cuando los lerrouxistas declaran la guerra abierta a los salmeronianos en Buenos Aires. Identificar a los "pacifistas", nombre con que Fuente bautizará a la corriente de Atienza, con los neutros es la primera estrategia para desplazarles de los órganos de dirección de la Liga.

Poco antes del mitin del Victoria, en septiembre, Fuente se había hecho ya cargo de la dirección de El Correo Español. En su primer artículo definió la política del órgano oficial de la Liga: no transigir con los indiferentes. Hubo en la colonia quien opinó que no se necesitaba un diario político, ni republicano ni monárquico, sino neutro, imparcial. Contra quien así pensara arremetió Fuente en sus artículos "Masculinos y neutros": se puede ser carlista pero no se puede ser neutro viendo el desconcierto en que vive España. Retoma aquí argumentos de Calzada en su carta abierta a Telesforo García, y avanza luego un paso más, rozando ya el insulto: neutros son los que tienen castrado el pensamiento, los pollos que no llegarán a gallos. “¿No quieren los neutros El Correo Español? Pues que no lo lean." ${ }^{40}$

Tuvieron razón los que pensaron que había condenado a muerte al diario. Aún sobrevivirá unos meses, para ser suplantado por El Diario Español de López de Gomara. Era Gomara el prototipo de neutro en Argentina: republicano de pensamiento pero de los que creían que España todavía no estaba preparada para la República. No faltaron roces entre los jacobinos de la Liga y sus "Páginas de España" de El Diario. Uno de los redactores de Gomara, que se escondía bajo el seudónimo de Capitán Verdades, estuvo a punto de acabar en los tribunales, acusado también por Malagarriga de difamación. ${ }^{41}$ Mientras el número de lectores de El Correo se iba reduciendo, el de las "Páginas de España", abiertas tanto a monárquicos como a republicanos, aumentó lo suficiente para que fuera viable separarlas de El Diario, naciendo así El Diario Español. ${ }^{42}$

Frente al bando de Malagarriga y Fuente, Atienza encontró un sólido apoyo en Francisco Grandmontagne, una de las figuras del 98 español que entonces residía en Argentina, y en Avelino Gutiérrez, prestigioso médico. Gracias a Grandmontagne, España pudo contar con colaboradores de la

39 La República Española, Buenos Aires, 6 de diciembre de 1903.

40 Reproducido en Fuente: Patria y República, pág. 50 y ss.

41 El Correo Español, Buenos Aires, 26 de abril de 1904.

42 Véase Villegas, Emilio F. de: Bosquejo histórico de El Diario Español, Buenos Aires, 1907. 
talla del argentino Miguel Cané o de Miguel de Unamuno y Ramiro de Maeztu, firmas que se unirían a las de Joaquín V. González, el hombre clave del segundo roquismo con quien Atienza mantiene estrecha relación, y a las de los institucionistas Francisco Giner, Rafael Altamira y Alfredo Calderón. ${ }^{43}$ Don Avelino, poco amigo de escribir, dejó no obstante constancia de sus planteamientos políticos: "El pasquín y el libelo no son armas de conquista", advirtió, en referencia tanto a los monárquicos como a los lerrouxistas. Lo que se ha de hacer es "propagar la idea, difundirla por todas partes, hacérsela comprender a los que no la entienden, enseñársela a los que no la saben, predicarla desde la prensa, desde la tribuna, de persona a persona, no perdiendo ocasión para hablar de ella y explicarla". ${ }^{44}$ Como Atienza, era de los pacifistas frente a los jacobinos. Estaba Gutiérrez en el bando de los seis del comité central que González de Salazar, antes de tiempo, había informado a Madrid que se habían retirado. No iban a resistir mucho más tiempo, atacados por las mordaces plumas de Malagarriga y Fuente.

A medida que el número de asistentes a las reuniones disminuye, el lenguaje de los lerrouxistas se endurece: la República se conquista con sangre. Los que salen con reparos monjiles, "esos castrados del pensamiento como muy bien los ha nombrado el señor Fuente", que se queden con los neutros, tronará Malagarriga. ${ }^{45}$

Unos meses después del mitin del Teatro Victoria, Atienza inició en España una serie de ocho artículos titulada "El alma española en América". A través de ellos pretendía explicar a los españoles de la Península cómo se veía España desde la excolonia, cómo era el alma española trasplantada a América y qué cooperación podían esperar de Argentina los republicanos españoles. Fueron sus capítulos V y VI los que precipitaron su salida de la Liga. Los trescientos mil españoles residentes en Argentina, argumenta, tienen fe en el resurgimiento de España, pero los políticos responden a esa fe con estériles debates que impiden hacer frente a los problemas reales:

43 Duarte (La república..., pág. 155) califica a Grandmontagne de peninsular en enero de 1904; de hecho, acababa de desembarcar en España, enviado a dictar unas conferencias por Atienza y la Patriótica y como corresponsal de La Prensa bonaerense; también en cuestión de detalle, da a Joaquín V. González por amigo de Calzada (pág. 60), cuando lo es de Atienza (véase González, Joaquín V.: Escritor y Maestro, Buenos Aires, 1907), y a Calzada por krausista (pág. 154) cuando es Atienza el que lo es; el afecto de González por la Liga al que se refiere Duarte (pág. 143) es en buena medida consecuencia de esa relación con Atienza. de 1903.

44 "La Liga Republicana Española", La República Española, Buenos Aires, 4 de octubre

45 Ibídem, 18 de octubre de 1903. 
fomentar la navegación y el comercio, e impulsar la educación nacional. Incluso la propaganda republicana no ha producido sino agitaciones espasmódicas. ${ }^{46}$

A estos dos artículos respondió Malagarriga en La República Española con otros dos. Primero se es republicano, escribe, y luego, cuando se llegue al poder, se será conservador o radical o federal. Esto es lo que se intentó en España con la Unión Republicana y lo que se consiguió en la Liga, todos sacrificando parte del programa propio en favor del esfuerzo colectivo. Puesto que en Buenos Aires podía decirse que no había monárquicos que combatir, la propaganda de la Liga se enfrentó a los neutros que con su apatía y acriollamiento eran los que impedían que el movimiento comprendiera a la totalidad. En su segundo artículo, observa críticamente la evolución de Atienza. En 1903, en el Teatro San Martín, increpaba a los que no eran republicanos. Ahora, en 1904, dice que el único resultado de la Unión Republicana ha sido producir agitaciones espasmódicas. ¿Qué dirá en 1905?, se pregunta, tratándole de apóstata, tránsfuga y apóstol de la inconsecuencia. Le recomienda se retire a La Prensa a escribir sobre cuestiones de enseñanza y política argentina ${ }^{47}$ Indalecio Cuadrado, secretario de la Liga y el más extremista del lerrouxismo platense, persiguió a Atienza hasta en la Patriótica. Protestó por carta ante la junta ejecutiva de que el presidente utilizara la revista para escribir artículos de orden personal, como si de un periódico político o de empresa se tratara. La junta no juzgó fundadas sus reclamaciones..$^{48}$

Atienza respondió a Malagarriga o, más bien, informó a través de España a sus amistades en la Península. No es la primera vez que Malagarriga había intentado agredirle, no sólo con la ironía y el pitorreo, sino también físicamente. "No ofende quien quiere sino quien puede", escribe. Detalla que no es él quien ha desertado del republicanismo, sino la dirección de la Liga, "influenciada por elementos levantiscos". Como ha salido él, añade con poco don profético, "tendrá que separarse antes de mucho el digno ciudadano que figura todavía al frente de esa organización”, es decir, Calzada. Para Atienza, los fines de la Liga eran, por un lado, levantar el censo e imponerse una pequeña cuestación mensual destinada a la Unión Republicana para la propaganda de sus ideas y la ejecución de sus

46 España, II, 63, Buenos Aires, 1904, pág. 5 y ss. de 1904.

47 "A un pacífico" y "Buen viaje", La República Española, Buenos Aires, 13 y 20 de octubre

48 Se publicó la carta en Ibídem, 16 de octubre de 1904. 


\section{IGNACIO GARCÍA}

planes; y por el otro, atraerse a los vacilantes y remisos. Había que convencer a los tibios, no a los adictos. Su línea no era sino la oficial de la Unión Republicana, que unos meses antes había llegado a un acuerdo de actuación parlamentaria con los liberales. Esta estrategia, reconoció, se había visto sofocada dentro de la Liga "por los heraldos de la furia intransigente apoyados en los dispuestos a seguir al que más grita" ${ }^{49}$

Malagarriga vuelve a tratarle de inconsecuente por defender en este artículo la república que había atacado en el otro y a desearle buen viaje. "Esta es mi penúltima palabra. La última, que debería referirse a ciertos deslices de pluma del doctor Atienza, no se dirá en el terreno periodístico". Atienza, retado a duelo, se escabullirá admitiendo que lo de "no ofende quien quiere sino quien puede" no era alusión personal sino genérica. ${ }^{50}$

\section{El Tesoro de la Liga}

La Liga se fundó para apoyar la Unión Republicana. El apoyo más eficaz que podía ofrecer, se dijo ya desde el principio, era económico. Al anunciarse el mitin del San Martín, El Infierno insistiría: "La revolución, para triunfar, solo necesita dinero, dinero y dinero, pues nos sobra todo lo demás. Los españoles en Argentina que no pueden ir a las barricadas ni a las elecciones porque se lo impide la distancia, deben contribuir con su dinero." ${ }^{51}$ Pacifistas y jacobinos estaban de acuerdo en ello, el desacuerdo se producía en el para qué o, más precisamente, para quién. La agresiva campaña de Malagarriga y Fuente tuvo siempre como objeto que estos fondos se destinaran a financiar los proyectos insurreccionales de Lerroux. Para eso viajó Fuente. El dinero fue ya el protagonista de su primer artículo en Argentina:

"Españoles en América, vosotros que habéis acudido siempre a los llamamientos de vuestros hermanos de España, acudid una vez más, sed generosos acá con vuestro dinero, como allí lo serán si es preciso con su sangre. . . Imitad a los irlandeses de los Estados Unidos, a los tabaqueros cubanos de la Florida, a los turcos y polacos de todo el mundo, que se sacrifican por el porvenir de sus patrias desde lejanas tierras". ${ }^{52}$

49 "Ingrato paréntesis en legítima defensa”, España, II, 64, Buenos Aires, 1904, pág. 20; sobre la línea oficial de la Unión Republicana, Suárez Cortina: El reformismo..., pág. 12.

50 La República Española, Buenos Aires, 2 de noviembre de 1904.

51 El Infierno, Buenos Aires, 13 de agosto de 1903.

52 La República Española, Buenos Aires, 15 de julio de 1903. 
Malagarriga, cansado al parecer de esperar que el comité central de la Liga lo hiciera, abrió él mismo una suscripción en julio de 1903 en $L a$ República Española, iniciándola con 15 pesos. No quita que puedan existir otras, todas acabarán en el Tesoro de la Liga, escribe: "Que nadie se arruine, pero que todos den." Puso la proverbial honestidad de Salmerón como garante del uso que se diera a ese dinero. ${ }^{53}$ La propuesta de Malagarriga no fue bien recibida por el comité central de la Liga; la propia revista no volvió a mencionar la suscripción. Era el momento idóneo para haberla hecho, cuando el entusiasmo era enorme, cuando toda la colonia se definía republicana, cuando gran número de comerciantes eran socios activos de la Liga. ¿Por qué no se hizo?

Para que Fuente pudiera canalizarlo hacia Lerroux había que neutralizar la tendencia salmeroniana en Buenos Aires y Atienza, como señalaba Salazar, gozaba de ascendente prestigio. Antes de que Atienza diera su apoyo a la suscripción, tenía que asegurarse de que los lerrouxistas no se apoderasen de ella. No se ganó Fuente la total confianza de Calzada que, aunque simpatizara con los jacobinos, consideraba el jefe de la Unión —no simplemente de nombre, sino de hecho- a Salmerón, y no a Lerroux. Los monárquicos crearon el rumor de que se mandó cierto dinero "a Salmerón" por esas fechas. La República Española despejó la calumnia, sin afirmar ni desmentir la noticia: los republicanos recogen fondos no para socorrer miserias sino para borrar miserias, explicaba, "y si se preguntase uno por uno a todos los donantes, tal vez dirían, "he dado el dinero para ayudar a que se haga la revolución"'. La desmentirá meses más tarde, poniendo a Atienza, ya retirado de la Liga, como testigo, ya que "entonces asistía a nuestras reuniones y que, según luego ha dicho, no estaba conforme con la marcha que los exaltados daban a la Liga [y, por lo tanto,] no hubiera dejado de levantar su voz" si se hubiera mandado. ${ }^{54}$

En todo caso, si no se mandó no fue por falta de empeño de Fuente. En abril de 1904, publicó su último artículo en Argentina. En él, se volvía a plantear el tema de la suscripción. Pidió que se comenzara sin esperar iniciativas de nadie, ni de Salmerón, ni del comité central de la Liga. Allá donde hubiera comité, que se sellase un pliego de papel y se encabezase: "Suscripción a favor de la República Española." Donde no lo hubiese, bastaba con que tres personas se juntasen e indicasen en el pliego la casa de comercio donde depositar los fondos recaudados. "Con esto basta para

53 Ibídem, 20 de julio de 1903.

54 Ibídem, 20 de septiembre y 8 de diciembre de 1904. 
seguridad de los donantes.” ¿Suscripción para el tesoro de la Unión Republicana? No lo aclara, ni pone a Salmerón como garantía. Escribe, simplemente: "Los centavos de los españoles de América serán la metralla con que se barrerá en España a la Monarquía traidora y a los políticos consentidores de la traición.” Anunciaba que La República Española publicaría cuantas listas de donantes se recibieran, pero ni se publicó ninguna, ni se volvió a mencionar la suscripción. Si Fuente vino a por dinero, por lo que la prensa republicana deja entrever, se fue sin un duro.

Obviamente, el comité central de la Liga no servía totalmente a los intereses del lerrouxismo, y Fuente no tuvo la seguridad de que, al partir él a España, la balanza en el seno de ese comité no se inclinara del lado de los pacifistas. Para asegurar un enlace directo, controlable entre el lerrouxismo y Buenos Aires, se creó el Centro Republicano Español, días antes de su partida: dentro de la Liga, para difundir las ideas de ésta, pero garantizando que pudiera hacer su propia política. Necesario, se dijo reutilizando a su servicio argumentos de Atienza, "no para estrechar nuestras filas sino para despertar a los indiferentes, decidir a los tibios y convencer a los neutros". Se inauguró a mediados de junio, bajo la presidencia honoraria de Calzada y real de Malagarriga..$^{55}$

En noviembre, por fin, se desplazaba a Atienza de la Liga. No había para los pacíficos función que desempeñar, había escrito, y de los procedimientos de los jacobinos "no quisimos hacernos cómplices desde el instante en que nos convencimos de nuestra impotencia para repararlos". ${ }^{56}$ Atienza se había quejado de que se predicaba para los adictos en lugar de salir a convencer a los indecisos y de que mientras en Uruguay se había recaudado dinero para la Unión Republicana, en Buenos Aires no se había hecho ni eso. Marginado Atienza, Malagarriga dio respuesta a ambas quejas. A la primera con el Centro; a la segunda, presionando ahora que ya tenía el control total para que se abriera la suscripción.

El martes 22 de noviembre, el comité central, por fin, la convocó. La inició Calzada con 10.000 pesos moneda nacional y en esa misma noche se

55 Ibídem, 19 de junio de 1904. En julio, Malagarriga asciende a presidente honorario, sustituyéndole como presidente el médico Ricardo Marín. Ibídem, 24 de julio de 1904. Al año siguiente, Marín se constituirá en el tercer presidente honorario, sustituyéndole al frente del Centro Indalecio Cuadrado. Ibídem, 23 de julio de 1904. El Centro, más que "la culminación del proceso organizativo de la Liga" (Duarte: La república..., pág. 110), fue una especie de primera escisión lerrouxista de la Liga; la segunda lo constituiría la fundación del Círculo Español Republicano de Cuadrado a finales de 1907.

56 España, II, Buenos Aires, 1904, pág. 20. 
suscribieron 20.000. En carta a los comités, Calzada la justificó porque "lo reclama de nosotros Salmerón en recientes comunicaciones". El Infierno intentó contagiar su semiinfantil entusiasmo: "Ha llegado el momento de poner a prueba el republicanismo de los españoles para ... lo que no debe decirse, porque está en el ánimo de todos los republicanos... Cada cual debe dar lo que pueda: el rico como rico y el pobre como pobre. Urge mandar dinero a Salmerón.” En La República Española, Malagarriga declara el inicio de la suscripción como la gran bomba que se ha arrojado en Buenos Aires sobre planes de los españoles monárquicos de iniciar otra para financiar el monumento isabelino. La campaña estuvo salpicada de referencias al grupo de Atienza a quien se acusa de sus pobres resultados: "una empresa que no siempre fue del lado de los enemigos donde halló los mayores

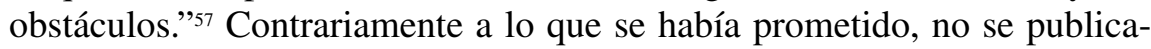
ron listas de donantes ni se hizo publicidad de las cantidades recaudadas, excepto la inicial.

El País de Madrid, en artículo de Fuente que reprodujo El Correo, calculó que se enviaría más de lo que se recaudó en el período 1896-1898. Obviamente una exageración que, aclaró en su siguiente número La República Española, tenía como exclusivo fin el asustar a la Monarquía. ${ }^{58}$ En velada organizada en enero de 1904 en el Casino Republicano de Madrid con ocasión del viaje de Ignacio Ares de Parga, uno de los vocales del Centro Republicano, Fuente defendió frente a la plana mayor del republicanismo español que en América no se creía en componendas y que se esperaba que la República naciera de una revolución: "Podéis creerlo, en la Argentina sólo se espera la orden del jefe pidiendo cuanto dinero sea necesario y señalando la fecha en que se debe enviar para emplearlo en la revolución." Intervino también el propio Salmerón. En un tono un tanto críptico, dice aceptar el Tesoro de la Liga, pero nada prefigura sobre el uso que se le vaya a dar:

“Agradezco los esfuerzos de las repúblicas del Río de la Plata en el sentido de formar un Tesoro para que podamos disponer de él cuando llegue el día de la acción; pero declaro que no recogeremos ese Tesoro sino cuando tengamos capacidad para emplearlo en el engrandecimiento, siquiera moral, de la patria España". ${ }^{99}$

57 Citas en El Correo Español, Buenos Aires, 23 de noviembre; El Infierno, Buenos Aires, 31 de noviembre de 1904; La República Española, Buenos Aires, 19 de enero de 1905, respectivamente; referencia al monumento isabelino en Ibídem, 22 de diciembre de 1904.

58 Ibídem, 8 de diciembre de 1904.

59 Ibídem, 11 de febrero y 19 de enero de 1905. 
No era un dinero que se estuviera recogiendo en Buenos Aires para lo que él decidiera y es más que probable que, a través de Atienza, el propio Salmerón lo sabía ya. El Correo del 12 de abril anunció la inesperada llegada de Fuente, trayéndole a Buenos Aires "asuntos mercantiles sin concluir". La República Española anunció su partida en su número del 27. $\mathrm{Ni}$ pronunció discurso, ni escribió artículo, ni se dio información otra sobre él. El 30 era la fecha indicada para el cierre de la suscripción, fecha que pasó inadvertida en la prensa republicana. Hay que recurrir a la memoria de Calzada para recomponer lo sucedido.

Fuente viajó llevando carta autógrafa de Lerroux, firmada también por Nicolás Estévanez, dirigida a él como jefe de la Liga, más otra personal. Según estas dos cartas y la información de Fuente, había llegado el momento de dar un golpe revolucionario: las personas ya estaban comprometidas, sólo faltaba el dinero. Calzada creyó la historia, lo cual no tiene nada de extraño. Lo que sí resulta extraño es que en aquel momento, 28 de abril, la Liga apenas tuviera fondos: tan sólo contaba con 1.561 pesos moneda nacional. La suscripción, que se abrió con 20.000 pesos en noviembre, se cerraba dos días después. ¿Dónde estaba ese dinero?60 Sigamos a Calzada: "Se acordó que yo anticipase la suma que era necesaria, corriendo el casi seguro riesgo de no reembolsarla, y se giró en el día telegráficamente por el Banco Alemán Trasatlántico.” ¿Que le llevó a enviar el dinero a Lerroux y no a Salmerón? La firma de Estévanez, nos dice, pesó en su decisión; su amistad databa de lejos: ya en 1890 había sido corresponsal de El Correo en París cuando Calzada era su director. Pero sobre todo pesó la indecisión de Salmerón:

"A todo esto, los correligionarios, todo el mundo, esperaban de España una palabra de aliento: la del jefe, la de Salmerón y Alonso. Yo le escribí cartas y cartas, anunciándole nuestra constitución, ofreciéndole dinero para el partido, hasta enviándole claves para que, por medio de ellas, pudiese pedir con toda cautela lo necesario, y Salmerón se fue al otro mundo sin decir nada, sin pedir nada. Aquel hombre era una esfinge....". ${ }^{61}$

Calzada sospechó si no habría pecado de exceso de candidez, pero prefirió considerar que si la revolución no se produjo fue por causas aje-

60 Ibídem, 14 de diciembre de 1904, apunta los problemas económicos que esta revista padecía; la situación del Centro Republicano no era tampoco boyante; cabe pensar que se utilizó para pagar deudas.

61 Calzada: Cincuenta años..., tomo II, págs. 240-242. 
nas a la voluntad de Lerroux y Estévanez. ¿Cuanto se envió? Martín Dedeu ofrece la cifra de 250.000 pesetas, algo más de 80.000 pesos. Pi y Suñer, que dijo fue quien traspasó la cantidad a España, la reduce a unas 36.000 pesetas. ${ }^{62}$ La operación, que la Liga mantuvo en el más estricto secreto, se divulgó en España con el consiguiente escándalo. Lo insignificante de la cantidad no cuenta. La Legación en Buenos Aires y el Gobierno en Madrid, tan interesados en minimizar la actuación de los emigrantes en 1903, cuando era realmente importante, la exagerarán ahora que habían constatado ya su esterilidad. De ahí en adelante, detrás de todos los rumores más o menos fundados sobre pronunciamientos y atentados contra Alfonso XIII, los periódicos monárquicos no dejarán de sacar a relucir "el oro de América".

\section{Calzada en España; Lerroux, en Argentina}

En la superficie, da la impresión que de 1905 a 1909 es cuando suceden los grandes acontecimientos: Rafael Calzada se presenta como candidato a Cortes en 1905 y le "roban" el acta; se vuelve a presentar en 1907 y marcha a Madrid como diputado. Lerroux viaja a Buenos Aires; Blasco Ibáñez, también, brindándosele un apoteósico recibimiento. Sin embargo, el republicanismo español en el Plata está ya huero, no hace sino vivir de las rentas de 1903.

La popularidad ganada con el asunto de "el oro de América" y el prestigio personal del propio Calzada llevaron al director de Las Dominicales del Libre Pensamiento de Madrid, el salmeroniano Fernando Lozano Montes, Demófilo, a proponerle como candidato republicano a las elecciones que habían de celebrarse el 10 de septiembre de 1905. Apoyaron la candidatura los federales, pues se le tenía por federal ${ }^{63}$ Llegado el día de las elecciones, nadie dudó del triunfo de Calzada, pero los periódicos del 13 llevaban ya la noticia, adelantada por el telégrafo, de que le habían quitado

62 Dedeu: "Dr Rafael Calzada", pág. 28. Pi y Suñer, sobrino de Francisco Suñer y Capdevila, afirmó en carta fechada en Gerona el 3 de mayo de 1907 y que reprodujo El Diario Español de Buenos Aires el 1 de junio siguiente, que Calzada dio orden al Banco Español en Rosario para que se girasen 26.400 francos.

63 La República Española, Buenos Aires, 27 de julio de 1905. El apoyo de Lerroux, obvio para Duarte (La república..., pág. 169) no lo es tanto; de hecho, el propio Calzado (Cincuenta años, tomo II, pág. 295), a pesar de sus simpatías por Lerroux, se negará ya en Madrid a abandonar a Salmerón porque considera que son los salmeronianos los que le han conseguido el escaño. 
el acta. Malagarriga envió a Madrid un "cablegrama bomba": "Diarios duélense triste espectáculo España ofrece en América consintiendo indignidades fines inconfesables. Colectividad siéntese burlada. Argentina deplora. Rafael Calzada personifica ideal hispano-americano." ${ }^{64}$ En La Prensa, Francisco Grandmontagne, su corresponsal en España, prometió "explicarlo todo", pero luego no lo hizo. Nos quedaremos, pues, con la versión del propio Calzada en sus Cincuenta años en América: su triunfo hacía imposible el de otro republicano, Luis Morote, que le seguía con pocos votos y Canalejas, amigo de éste, presionó para que en el escrutinio se invirtiesen los términos, quedando sin acta, por esos mismos pocos votos de diferencia, el propio Calzada. ${ }^{65}$

La Unión Republicana consiguió a nivel nacional treinta diputados, seis menos que en la legislatura anterior. Los entusiasmos de 1903 se habían evaporado también en España. El posterior acercamiento de Salmerón a los catalanistas tuvo un curioso efecto en la Liga. Por un lado, enfrió el lerrouxismo de Malagarriga, nacido en Barcelona y defensor del catalanismo. Por otro, los lerrouxistas, ahora encabezados por Indalecio Cuadrado, que desde julio de 1904 presidía el Centro Republicano, ganaron las simpatías de aquellos que miraban con recelo los movimientos regionalistas. ${ }^{66}$ Calzada continuó con su posición ecléctica: aún simpatizando con Lerroux, aún no entendiendo el acercamiento de Salmerón a los catalanistas, no estaba dispuesto a traicionar al jefe de la Unión. Su candidatura por Madrid volvió a ser proclamada en las elecciones de abril de 1907. También en esta ocasión trató de escamoteársele el acta con la complicidad de otros candidatos republicanos, pero lo evitó la decidida postura de Benito Pérez Galdós, que amenazó con renunciar si tal se hacía. ${ }^{67} \mathrm{~A}$ su llegada a la estación de Mediodía de Madrid el 5 de diciembre fue recibido por millares de personas que, empeñados en acompañarle en su recorrido al hotel, fueron dispersados a sablazos por la policía. Dos días después se detuvo en Madrid a un grupo de sargentos, por suponérseles conspiradores: la prensa monárquica sospechó de Calzada y no faltaron referencias a "el oro de América".

64 La República Española, Buenos Aires, 14 de septiembre de 1905.

65 Calzada: Cincuenta años..., tomo II, pág. 245.

66 Sobre su catalanismo, véase Malagarriga, Carlos: "Mi España, mi Cataluña”, España, II, 25, Buenos Aires, 1904; también Rocamora, Joan: Catalanes en la Argentina. Centenario del Casal de Catalunya, Buenos Aires, 1992, págs. 170-171.

67 El Diario Español, Buenos Aires, 23 y 24 de abril de 1907. 
En el Congreso, Calzada se destacó por su activa campaña de obstrucción a los proyectos de Ley de la Administración Local y de Ley sobre Represión del Terrorismo de Maura. ${ }^{68}$ La renuncia de Salmerón en 1908 dejó el partido acéfalo, y hubo quien propuso a Calzada para reemplazarle. La asamblea de la Unión Republicana que se celebró, a petición del propio Calzada, en mayo de 1908 le incluyó en el directorio de cuatro personas. Calzada no aceptó el reto. Aprovechando las vacaciones de verano del Congreso volvió a Buenos Aires, y no cumplió su promesa de retornar. ${ }^{69}$

En Buenos Aires, su ausencia no había hecho sino agravar las tensiones. Indalecio Cuadrado, al que Calzada finalmente recordará como "un rebelde, en el fondo, un redomado anarquista", se empeñó en que la Liga debiera aceptar como jefe a Lerroux, ya separado de la Unión. Finalmente, el grupo de Cuadrado se escindió formando el Círculo Español Republicano y la Liga, presidida por Malagarriga, continuó apoyando la política de Calzada. Su consejo general aprobó el 26 de marzo de 1908 un proyecto de "programa único" que se pretendía que Malagarriga presentase en Madrid; pero la otrora origen del mito de "el oro de América" no tenía ahora fondos ni para pagarle el viaje. ${ }^{70}$

Sí viajó, en dirección contraria, Alejandro Lerroux, que llegó a Buenos Aires el 29 de septiembre de 1908. Un pequeño grupo de correligionarios fue al puerto a esperarle. La Liga le ofreció una recepción en el Club Español y un par de banquetes en Buenos Aires y Rosario; después, el grupo de Cuadrado lo "secuestró", en expresión de Calzada. Durante unos meses se dedicó a negocios de libros, lámparas y vinos, estrechamente vigilado por la Legación. ${ }^{71}$ La fría recepción dada a Lerroux contrastó con la multitudinaria que se brindó al también ex diputado republicano Vicente Blasco Ibáñez en junio de 1909, pero a éste se le recibió más como novelista y hombre de cultura que como político.

La presencia de la Infanta Isabel de Borbón en los actos del Centenario en mayo de 1910 marcó el fin del movimiento iniciado en 1903: el propio Malagarriga, sin otro púlpito ahora que el de El Diario Español, se volverá telesforista: "Las ideas políticas aquí no cuentan... seamos todos españoles."’72

68 Calzada: Cincuenta años..., tomo II, págs. 275 y ss, y 284-314.

69 Deja constancia de que prometió volver en Ibídem, tomo II, pág. 344; renunció a su acta en mayo de 1909, El Diario Español, Buenos Aires, 23 de mayo de 1909.

70 Calzada: Cincuenta años..., tomo II, págs. 306-307.

71 AMAE, 1355. Despachos fechados el 4 de febrero, el 20 de mayo y el 24 de junio de 1909.

7217 de mayo de 1910 . 


\section{Conclusión}

El paso de Calzada por las Cortes fue el último coletazo de ese movimiento, y las visitas de Lerroux y Blasco Ibáñez, sólo anécdota, lo que prueba que la historia no siempre se revela en los titulares de los periódicos y que hay que escarbar también en la letra pequeña. En este artículo, y escarbando sobre todo en España, hemos añadido al planteamiento de $L a$ república del emigrante el punto de vista de Atienza. Duarte da por buena la versión de La República Española, es decir, la de los lerrouxistas. Ignora la que presenta el ala salmeroniana, peor todavía, la lee a través de los ojos tendenciosos de Malagarriga, o de los tampoco inocentes de la Legación. Con Fuente y Malagarriga, considera también a Atienza neutro, cuando neutro es el insulto con el que aquellos le califican. Los bandos no son Atienza y Gomara (los neutros) frente a la Liga y Calzada (los verdaderos republicanos) como, siguiendo a Malagarriga, Duarte repetidamente los dibuja; ${ }^{73}$ los bandos son: fuera de la Liga, los neutros (Gomara, por poner el ejemplo más claro), y dentro de ella los salmeronianos (Atienza) y los lerrouxistas (hasta 1907, Malagarriga), con Calzada flotando entre los dos.

$\mathrm{Ni}$ jacobinos ni pacifistas podían haber ganado una batalla que se peleaba a miles de kilómetros. La Liga no podía ella sola echar al rey, de la misma manera que la Patriótica tampoco pudo una década antes cambiar el rumbo de la guerra en el Caribe. Sin embargo, no se puede por menos de admirar el respeto a la verdad y sobre todo la transparencia de que hace gala en 1903-05 el sector pacifista de la Liga, eco de esa transparencia que tanto ayudó al éxito de la Patriótica en 1896-98. El que, en especial desde el punto de vista económico, la actuación de la Liga se tornara estéril se debió a las campañas de difamación de los jacobinos (precisamente presentando como neutros a los salmeronianos), a su falta de transparencia (patente en las cuentas del Tesoro), a su recurso a la exageración, al insulto y a la amenaza (la Liga recaudará más que la Patriótica, se escribe; se les llama castrados en lugar de masculinos; se trata de silenciar a Atienza hasta con pistola). Una vez más, estamos aquí ante una versión particular del universal dilema sobre si los medios deben ajustarse al fin o el fin los justifica, solución esta última que suele encontrar defensores en nombre del pragmatismo y la eficacia. La historia de la Liga prueba que tal fama no es siempre merecida.

73 Duarte: La república..., págs. 48, 151, 153 (en especial nota 35), 174-175, etc. 
Estableciendo de nuevo el paralelismo con el que comenzábamos, no se discute aquí cómo les fue a los estalinistas con "el oro de Moscú", pero parece claro que a los lerrouxistas, la victoria con "el oro de América" les resultó pírrica. La apología que les hace Duarte en su por lo demás valioso trabajo, ignorando o tergiversando la posición de los pacifistas, ha de ser consecuencia de esa superficialidad que le atribuíamos y que le lleva a dar por buena la primera versión que le llega. Porque ha llovido ya mucho desde entonces como para pensar que lo haya hecho por militancia. 